\title{
Microsurgical Advancements in Breast Reconstruction
}

\author{
Alice Grant ${ }^{1,2,}{ }^{,}$, Matthew Binks ${ }^{2,3}$ \\ ${ }^{1}$ John Hunter Hospital, Newcastle, Australia \\ 2 University of New South Wales, Sydney, Australia \\ ${ }^{3}$ Nepean Hospital, Sydney, Australia
}

Corresponding Author: Alice Grant, MD, John Hunter Hospital, Newcastle, Australia. E-mail: agra7230@uni.sydney.edu.au

Received May 24, 2017; Accepted June 12, 2017; Online Published August 29, 2017

\begin{abstract}
Breast cancer is the most common cancer diagnosed in women worldwide, and studies are now demonstrating an increased incidence in recent years. Despite this, mortality rates for breast cancer remain low, with many women living many years beyond their cancer diagnosis. Therefore, there is a need for durable reconstructive options. Approximately $40 \%$ of women diagnosed with breast cancer will undergo a mastectomy as part of their initial treatment plan. Breast reconstruction has been consistently shown to improve post-mastectomy quality of life. Despite this, breast reconstruction rates, both in the immediate and delayed setting, remain low. With advancements in microsurgery over the past few decades, autologous tissue reconstruction has become an attractive option for breast cancer survivors offering them the benefits of a more natural aesthetic and permanency over implantbased surgery. This review provides a report on avant-garde microsurgical breast reconstruction techniques and insight into some of the benefits and drawbacks associated with each surgical approach.

Keywords: Cancer; Mastectomy; Breast Reconstruction; Surgery

Citation: Grant A, Binks M. Microsurgical advancements in breast reconstruction. Int J Med Rev. 2017;4(3):76-80. doi: 10.29252/ijmr-040304.
\end{abstract}

\section{Introduction}

Breast cancer is the most commonly diagnosed cancer in women accounting for approximately $30 \%$ of new cancer diagnoses. ${ }^{1}$ Studies now demonstrate an increased incidence in recent years with 268,670 new diagnoses expected in the United States in 20181. Forty percent of those diagnosed with invasive breast cancer will then proceed to mastectomy. ${ }^{2}$ Numerous studies have now demonstrated that undergoing reconstruction of the breast after the initial mastectomy increases quality of life by enhancing psychological wellbeing in breast cancer patients, ${ }^{3,} 4$ yet despite this, rates for reconstruction remain low worldwide, with rates ranging from $12 \%$ in Australia ${ }^{5}$ up to $25 \%$ in the United States and United Kingdom. ${ }^{6}$ Reconstructive options are varied and include implant-based methods, autologous flap repair, or techniques that utilize both methods and are undertaken either as part of the initial surgery in the form of immediate reconstruction or as a delayed surgery. Recent studies have indicated that both immediate and delayed forms of reconstruction are considered "oncologically safe" 7 in the majority of patients. With advancements in microsurgery over the past few decades, autologous tissue reconstruction has become an attractive option for breast cancer survivors offering them the benefits of a more natural aesthetic and permanency over implant-based surgery.
Evolution of the Microsurgical Approach to Autologous Breast Reconstruction
In the early 1960s, the breast implant was introduced, pioneered by Cronin and Gerow, and marked the advent of modern breast reconstructive surgery. ${ }^{8}$ Autologous methods followed a decade later when Schneider, Hill, and Brown reintroduced the latissimus dorsi tissue flap for breast surgery in $1977 .{ }^{9}$ One of the major pitfalls of the latissimus dorsi flap was the inadequate flap size, with surgeons often having to combine the flap with an implant. Attention then turned to the abdomen, which allowed for the transfer of larger tissue volumes and the additional benefit of enhanced abdominal contour, making it the ideal site to harvest tissue for breast reconstructive surgery. In 1979, Australian surgeon Robbins described the use of a vertically-orientated myocutaneous flap involving the rectus abdominus to recreate the breast following mastectomy, ${ }^{10}$ and in 1982 Hartrampf et al. presented their pedicle-based flap involving a transversely orientated rectus abdominus

Copyright (C) 2017 The Author(s). This is an open-access article distributed under the terms of the Creative Commons Attribution License (http://creativecommons.org/licenses/by/4.0), which permits unrestricted use, distribution, and reproduction in any medium, provided the original work is properly cited. 
and skin, which later became recognized as the transverse rectus abdominus myocutaneous (TRAM) flap. $^{11}$

Concurrently with the development of microsurgical techniques, Taylor and Daniel introduced the concept of the "free flap" in 1973, which was based on the premise of transferring an island of tissue to a distant site through microvascular anastomosis. ${ }^{12}$ Based on this knowledge, the free TRAM flap was then described later that decade and went on to form the basis of modern free flap breast reconstructive surgery. ${ }^{13}$ The major limitation of these early flaps was the excessive amount of muscle transferred, which led to large donor site defects and delayed healing. Consequently, flaps were then created with decreasing volumes of rectus abdominus, and the notion of TRAM flaps that were muscle-sparing was conceived. ${ }^{14}$ It later became clear that limiting donor site morbidity had benefits that would extend beyond abdominal wall hernias and bulges. This led to the landmark study by Koshima and Soeda ${ }^{15}$ in 1989 , which described the possibility of utilizing only skin and abdominal fat and sparing muscle by carefully dissecting small perforating vessels derived from the deep inferior epigastric vessels by crossing but not excising fascia or rectus abdominus. Following on from this, Allen and Treece $^{16}$ in 1994 successfully reconstructed the breast without any muscle, utilizing fat and skin from the lower abdomen based on small perforating vessels originating from the inferior epigastric artery, and thus put forward the deep inferior epigastric perforator (DIEP) flap, which is now the main option to the free TRAM flap in autologous breast reconstructive surgery.

\section{Anatomy and Rationale of Flaps Based on Perforating Vessels in Reconstructive Breast Surgery}

Both the TRAM and DIEP flaps are based on the same vessels: the deep inferior epigastrics. ${ }^{17}$ The deep inferior epigastric artery gives rise to both lateral and medial branches on both sides of the abdomen, which then give rise to several small perforators that supply the skin and subcutaneous fat over the lower abdomen. ${ }^{17}$

To perform a DIEP flap, standard abdominoplasty markings are made; perforators are often identified prior to surgery with duplex ultrasound or CT angiography. ${ }^{18}$ The flap is then raised usually lateral to medially with careful identification of the lateral perforators with the flap then based on the largest perforator and possibly an additional one to two smaller perforators in order to gain its entire blood supply. The sheath of rectus abdominus muscle is then entered, and using microsurgery, the small perforating vessels are traced intra-muscularly through the rectus abdominus to their source, the deep inferior epigastric vessels, ensuring an adequate pedicle length of approximately $10 \mathrm{~cm} .{ }^{17}$

Under the microscope, the artery and vein are tied, and then the tissue flap is brought up to the chest wall. The tissue is then used to reconstruct the chest wall defect secondary to the mastectomy. This is performed through the anastomosis of the donor vessels to the internal mammary vessels (or occasionally thoracodorsal vessels) using an end-to-end approach typically using the second or third intercostal space. ${ }^{17}$ The arterial anastomosis is typically hand sewn with a $9 / 0$ or $10 / 10$ nylon suture; however, in many centers where venous discrepancy is encountered, a venous coupling device is employed to carry out the venous anastomosis. Recent studies have shown the use of this device to have higher patency rates than standard suture techniques. ${ }^{19}$ The abdominal defect is then closed primarily with no mesh required in the majority of cases.

The most recent perforator-based abdominal flap is the superficial inferior epigastric artery (SIEA) flap, which has gained momentum in recent years due to low rates of donor site complications. As the flap is raised, the superficial inferior epigastric vessels can be assessed and, if deemed adequate, used as the primary vessels for flap vascularisation and anastomosis. ${ }^{17}$ Given the anatomic location of these vessels, the surgeon does not need to alter the sheath nor the rectus abdominus muscle, thereby providing a free flap technique that is less invasive compared with the DIEP and TRAM flaps. Furthermore, the SIEA technique provides the surgeon with adaptability; if the vessels are noted to be of insufficient size, the surgeon can easily convert to performing the DIEP or TRAM techniques as previously described.

\section{Donor Site Morbidity}

There is ongoing debate whether perforator-based flaps, such as the deep and superficial epigastric flaps, are in fact superior to the TRAM flap regarding morbidity of the donor site, which is of paramount importance in breast reconstructive surgery.

Supporters of the muscle-conserving TRAM flap suggest that if the flap is well executed, a very small cuff of muscle containing the pedicle is required and incorporated into the flap with the majority of the rectus left. They argue that this is essentially equivalent to the disruption that occurs when carrying out the intra-muscular dissection performed during a DIEP flap. Recent studies have shown similar rates of abdominal wall morbidity when comparing the two techniques. ${ }^{20,21}$

Proponents of the DIEP flap, however, point to a study recently carried out that demonstrated those who underwent the DIEP flap had a 50\% decreased risk of developing an abdominal wall hernia or bulge in contrast to patients who underwent a flap repair with a TRAM approach (RR 0.49 CI 95\%, 0.28-0.86, p=0.57). ${ }^{22}$

Furthermore, two additional studies showed superior abdominal wall strength in patients who underwent the DIEP technique compared with patients who received a TRAM flap. ${ }^{23,24}$ Although evidence is lacking due to the relative infancy of the SIEA flap, results regarding 
abdominal wall morbidity appear promising. A recent study indicated a statistically significant improved lifting ability in the post-operative period $(\mathrm{p}=0.02)$ in patients who underwent a SIEA flap compared with patients who received a TRAM flap, ${ }^{25}$ however, these results were not statistically significant when compared with DIEP patients. Another benefit of perforator-based flaps, though secondary to minimal fascial and rectus abdominus disruption, is decreased post-operative pain and shorter recovery times. Another study recently demonstrated that patients who underwent a DIEP flap had reduced opioid analgesic requirements in the postoperative period and shorter hospital stays compared with those who underwent a free TRAM flap (mean = 4.73 days versus 5.21 days, $\mathrm{p}=0.026){ }^{26}$

\section{Flap Related Morbidity}

In autologous reconstructive techniques, an ideal flap is regarded as one with good reliability that takes into consideration the natural aesthetics and contours of breast tissue and has minimal donor site complications. While the perforator flaps appear attractive from the perspective of limiting abdominal wall morbidity, they are based on fewer perforating vessels than the TRAM flap, and thus, in theory, this could translate to decreased vascularization of the flap and a higher degree of flaprelated morbidity ${ }^{22}$. Numerous studies over the past decade have evaluated this, focusing particularly on the rates of necrosis of fatty tissue, partial and complete flap failure, and venous congestion. A recent study which compared the flaps showed no significant disparity in rates of venous congestion, necrosis, or flap failure between perforator flaps and free TRAM flaps. ${ }^{27}$ Furthermore, the researchers also demonstrated in a follow-up study that compared an equal number of patients who underwent a unilateral DIEP flap and those who received a unilateral TRAM muscle conserving flap (ms-free TRAM) that rates of flap-related morbidity were statistically similar among both groups of patients (fat necrosis: $6.4 \%$ in DIEP flaps versus $7.1 \%$ in $\mathrm{ms}$-free TRAM p $>0.74$, venous congestion: $4.5 \%$ in DIEP versus $2.7 \%$ ms-free TRAM p $>0.61$, flap failure: $2.5 \%$ DIEP flaps versus $1.8 \%$ in ms-free TRAM $\mathrm{p}>0.61) .^{20}$

More recent studies, however, have shown higher flaprelated morbidity for perforator-based flaps. In a recent meta-analysis, there was a twofold increase in necrosis of fat tissue in those patients who received the perforator DIEP flap compared with those who received the TRAM free flap (RR 1.94; 95\% CI, 1.28-2.93, p=0.07) and a twofold increase in flap death among those who underwent a perforator DIEP flap (RR 2.05; 95\% CI, 1.16-3.61; $\mathrm{p}=0.04) .^{22}$ The rationale behind this increased flap morbidity as mentioned previously may be related to perforator number rather than flap type. A recent study showed that fat necrosis rates were highest in flaps containing fewer perforators and lowest in flaps containing 3-5 perforators, independent of flap type. ${ }^{28}$
Perforator number may be only one factor that determines flap morbidity. Other studies have suggested that anatomical variations, particularly of the superficial inferior epigastric vein, also play a role. ${ }^{29}$

\section{The Tailoring of Flaps in Autogenous Breast Reconstruction}

Analyzing the data given above, it becomes clear that the evidence is not completely one-sided. While free myocutaneous flaps may have overall lower rates of flap morbidity in large studies, this appears to come at the expense of donor site morbidity. Given this finding, it is imperative to take into account pre-operative and intraoperative factors for each individual patient when deciding on which flap to utilize and the timing of autologous reconstruction. Pre-operative factors include breast volume and smoking status. Some centers prefer to undertake a free TRAM over a DIEP flap for patients with breast volumes greater than $1000 \mathrm{CC}$ or a positive smoking history due to the proposed improved vascularity through the higher number of perforators with the free TRAM flap. ${ }^{20}$ Additionally, tumor stage and nodal status, which are important determinants in assessing a patient's need for radiotherapy, are also important considerations. Most centers now perform autologous reconstruction as a delayed procedure for patients undergoing radiotherapy because of higher rates of radiation-induced fibrosis when performed prior to radiotherapy. ${ }^{30}$ Finally, intra-operative factors and the surgeons' clinical judgement as they progress through the surgery are of paramount importance in determining flap choice. Granzow et al. noted that they often base their flap choice on the anatomy encountered during flap harvesting; for example, in patients noted to have sufficient superior inferior epigastric vessels, they will proceed with a SIEA flap over a DIEP flap. ${ }^{17}$ Other centers, however, propose conversion to a free TRAM over a DIEP flap when an insufficient amount or calibre of deep perforating vessels is encountered intraoperatively. $^{20}$

\section{Conclusions}

Numerous studies have now demonstrated the positive effect that breast reconstruction may have on breast cancer survivors, yet rates of reconstruction remain low, particularly in Australia, possibly secondary to low referral rates to appropriate centers and lack of information received by the patient from the primary surgeon ${ }^{6}$. With recent developments in microsurgery and through a deeper understanding of the anatomy of autologous tissue transfer, free flaps now represent an increasingly favorable method of breast reconstruction and may significantly contribute to improved reconstruction rates in the near future, offering overall fairly low rates of donor and flap morbidity and the ability to tailor a flap based on an individual patient's needs. 


\section{Authors' Contributions}

AG was the primary writer of the article and $\mathrm{MB}$ was editor and advisor.

\section{Conflict of Interest Disclosure}

The authors declare that they have no conflicts of interest.

\section{Funding}

None.

\section{References}

1. Siegel RL, Miller KD, Jemal A. Cancer statistics, 2016. CA Cancer J Clin. 2016;66(1):7-30. doi: 10.3322/caac.21332. pmid: 26742998

2. Roder D, Zorbas H, Kollias J, Pyke C, Walters D, Campbell I, et al. Factors predictive of treatment by Australian breast surgeons of invasive female breast cancer by mastectomy rather than breast conserving surgery. Asian Pac J Cancer Prev. 2013;14(1):539-45. pmid: 23534791.

3. Wehrens KME, Cuypers WJSS, Boeckx WD, van der Hulst RRWJ. Psychological profile of women seeking breast reconstruction and quality of life assessment after surgery. Eur J Plast Surg. 2005;28(4):264-7. doi: 10.1007/s00238004-0709-8.

4. Elder EE, Brandberg $\mathrm{Y}$, Bjorklund $\mathrm{T}$, Rylander R, Lagergren J, Jurell G, et al. Quality of life and patient satisfaction in breast cancer patients after immediate breast reconstruction: a prospective study. Breast. 2005;14(3):201-8. doi: 10.1016/j.breast.2004.10.008. pmid: 15927829.

5. Breast Cancer Network Australia. Breast Reconstruction Survey 2010 [updated November 201020 April 2015]. Available from: https://www.bcna.org.au/sites/default/files /breast-reconstruction-report.pdf.

6. Wong A, Snook K, Brennan M, Flitcroft K, Tucker M, Hiercz $D$, et al. Increasing breast reconstruction rates by offering more women a choice. ANZ J Surg. 2014;84(1-2):31-6. doi: 10.1111/ans.12471. pmid: 24450788

7. Gieni M, Avram R, Dickson L, Farrokhyar F, Lovrics P, Faidi $S$, et al. Local breast cancer recurrence after mastectomy and immediate breast reconstruction for invasive cancer: a metaanalysis. Breast. 2012;21(3):230-6. doi: 10.1016/j.breast.20 11.12.013. pmid: 22225710.

8. Hohler H. [Carcinoma of the breast. Reconstructive surgery]. Langenbecks Arch Chir. 1977;345:78-86. pmid: 593020.

9. Schneider WJ, Hill HL, Jr., Brown RG. Latissimus dorsi myocutaneous flap for breast reconstruction. Br J Plast Surg. 1977;30(4):277-81. pmid: 338072.

10. Robbins TH. Rectus abdominis myocutaneous flap for breast reconstruction. Aust N Z J Surg. 1979;49(5):527-30. pmid: 159684.

11. Hartrampf CR, Scheflan M, Black PW. Breast reconstruction with a transverse abdominal island flap. Plast Reconstr Surg. 1982:69(2):216-25. pmid: 6459602.

12. Daniel RK, Taylor GI. Distant transfer of an island flap by microvascular anastomoses. A clinical technique. Plast Reconstr Surg. 1973;52(2):111-7. pmid: 4578998.

13. Holmstrom $\mathrm{H}$. The free abdominoplasty flap and its use in breast reconstruction. An experimental study and clinical case report. Scand J Plast Reconstr Surg. 1979;13(3):423-27. pmid: 396670.

14. Feller AM. Free TRAM. Results and abdominal wall function. Clin Plast Surg. 1994;21(2):223-32. pmid: 8187416.

15. Koshima I, Moriguchi T, Soeda S, Tanaka H, Umeda N. Free thin paraumbilical perforator-based flaps. Ann Plast Surg. 1992;29(1):12-7. pmid: 1386718.
16. Allen RJ, Treece P. Deep inferior epigastric perforator flap for breast reconstruction. Ann Plast Surg. 1994;32(1):32-8. pmid: 8141534

17. Granzow JW, Levine JL, Chiu ES, Allen RJ. Breast reconstruction with the deep inferior epigastric perforator flap: history and an update on current technique. J Plast Reconstr Aesthet Surg. 2006;59(6):571-9. doi: 10.1016/j.bjps.2006.01.004. pmid: 16716950.

18. Keys KA, Louie O, Said HK, Neligan PC, Mathes DW. Clinical utility of CT angiography in DIEP breast reconstruction. J Plast Reconstr Aesthet Surg. 2013;66(3):e61-5. doi: 10.1016/j.bjps.2012.09.025. pmid: 23084649.

19. Jandali S, Wu LC, Vega SJ, Kovach SJ, Serletti JM. 1000 consecutive venous anastomoses using the microvascular anastomotic coupler in breast reconstruction. Plast Reconstr Surg. 2010;125(3):792-8. doi: 10.1097/PRS.0b013e3181c b636d. pmid: 20195107.

20. Nahabedian MY, Tsangaris T, Momen B. Breast reconstruction with the DIEP flap or the muscle-sparing (MS2) free TRAM flap: is there a difference? Plast Reconstr Surg. 2005;115(2):436-44; discussion 45-6. pmid: 15692347.

21. Bajaj AK, Chevray PM, Chang DW. Comparison of donorsite complications and functional outcomes in free musclesparing TRAM flap and free DIEP flap breast reconstruction. Plast Reconstr Surg. 2006;117(3):737-46; discussion 47-50. doi: 10.1097/01.prs.0000200062.97265.fb. pmid: 16525 258.

22. Man LX, Selber JC, Serletti JM. Abdominal wall following free TRAM or DIEP flap reconstruction: a meta-analysis and critical review. Plast Reconstr Surg. 2009;124(3):752-64. doi: 10.1097/PRS.0b013e31818b7533. pmid: 19342994.

23. Blondeel N, Vanderstraeten GG, Monstrey SJ, Van Landuyt $\mathrm{K}$, Tonnard P, Lysens R, et al. The donor site morbidity of free DIEP flaps and free TRAM flaps for breast reconstruction. Br J Plast Surg. 1997;50(5):322-30. pmid: 9245865.

24. Futter CM, Webster MH, Hagen S, Mitchell SL. A retrospective comparison of abdominal muscle strength following breast reconstruction with a free TRAM or DIEP flap. Br J Plast Surg. 2000;53(7):578-83. doi: 10.1054/bjps. 2000.3427. pmid: 11000074.

25. Wu LC, Bajaj A, Chang DW, Chevray PM. Comparison of donor-site morbidity of SIEA, DIEP, and muscle-sparing TRAM flaps for breast reconstruction. Plast Reconstr Surg. 2008;122(3):702-9. doi: 10.1097/PRS.0b013e3181823c15. pmid: 18766032.

26. Kroll SS, Sharma S, Koutz C, Langstein HN, Evans GRD, Robb GL, et al. Postoperative morphine requirements of free TRAM and DIEP flaps. Plast Reconstr Surg. 2001;107(2):33841. pmid: 11214047.

27. Nahabedian MY, Momen B, Galdino G, Manson PN. Breast Reconstruction with the free TRAM or DIEP flap: patient selection, choice of flap, and outcome. Plast Reconstr Surg. 2002;110(2):466-75; discussion 76-7. pmid: 12142662.

28. Baumann DP, Lin HY, Chevray PM. Perforator number predicts fat necrosis in a prospective analysis of breast reconstruction with free TRAM, DIEP, and SIEA flaps. Plast Reconstr Surg. 2010;125(5):1335-41. doi: 10.1097/PRS.0b013e3181d4fb4a. pmid: 20440154.

29. Blondeel PN, Arnstein M, Verstraete K, Depuydt K, Van Landuyt $\mathrm{KH}$, Monstrey SJ, et al. Venous congestion and blood flow in free transverse rectus abdominis myocutaneous and deep inferior epigastric perforator flaps. Plast Reconstr Surg. 2000;106(6):1295-9. pmid: 11083558.

30. Berbers J, van Baardwijk A, Houben R, Heuts E, Smidt M, Keymeulen K, et al. 'Reconstruction: before or after postmastectomy radiotherapy?' A systematic review of the literature. Eur J Cancer. 2014;50(16):2752-62. doi: 10.1016/j.ejca.2014.07.023. pmid: 25168640. 